\title{
Methoden zur Fahrersicht-Optimierung am Beispiel des neuen Opel ASTRA
}

Dr. Lars Woyna, Adam Opel AG

Vortrag lag zu Redaktionsschluss nicht vor.

Vielen Dank für Ihr Verständnis. 